\title{
O IMPACTO DE UM SISTEMA DE AGENDAMENTO ANTECIPADO DE DOCAS PARA CARGA E DESCARGA NA GESTÃO DA CADEIA DE SUPRIMENTOS
}

\section{THE EFFECT OF A DOCK SCHEDULE SYSTEM IN ADVANCE FOR SHIPMENT AND RECEIVING IN THE SUPPLY CHAIN MANAGEMENT}

\author{
Fabrício Mello Mulato \\ Engenheiro de Produção e Especialista em Administração de Empresas \\ Universidade de São Paulo - USP \\ Faculdade de Economia, Administração e Contabilidade - FEA-RP \\ Avenida dos Bandeirantes, 3900 - Ribeirão Preto - SP - Brasil
}

(16) 3632-7295 - fmulato@ yahoo.com

\section{Marcio Mattos Borges de Oliveira \\ Professor Associado \\ Universidade de São Paulo - USP}

Faculdade de Economia, Administração e Contabilidade - FEA-RP

Avenida dos Bandeirantes, 3900 - Ribeirão Preto - SP - Brasil

(16) 3602-3939 - mmattos@usp.br

\begin{abstract}
RESUMO
O agendamento antecipado de docas para recebimento e expedição de veículos pode gerar grandes benefícios para todos os envolvidos na cadeia de suprimentos, por meio de melhorias na eficiência, na utilização dos recursos, no fluxo de cargas e na visibilidade. Tempos de espera ao redor das docas têm como conseqüência a perda de receitas, custos extras, insatisfação de motoristas e alta rotatividade de funcionários para as transportadoras. Este artigo procura mostrar porque alguns aspectos relacionados ao agendamento e programação de docas não podem ser subestimados e como esse conceito pode trazer efeitos positivos que se transformam em vantagem competitiva. Para ilustrar os benefícios dessa prática, foram realizados estudos de casos em empresas que implantaram um sistema informatizado para este tipo de problema. Nos estudos de casos, observou-se que a ferramenta implementada trouxe melhorias nas variáveis analisadas: a distribuição mais uniforme dos carregamentos ao longo do mês e a redução do tempo médio de permanência dos veículos.
\end{abstract}

Palavras-chaves: Agendamento de docas, Cadeia de Suprimentos, Logística. 
ABSTRACT

The anticipated dock's scheduling for the cars' arrival and shipment can generate great benefits for everyone involved in the supply chain, by means of efficiency improvements in the resources' usage, in the cargo flow and in the visibility. Waiting periods around the docks have as consequence income loss, extra costs, driver's dissatisfaction and high transporter employees' rotation. This article seeks to show why some aspects related to the docks' scheduling and promotion cannot be underestimated and how this concept can cause positive effects that become competitive advantage. To illustrate this method's benefits, case studies were done in companies which implemented computerized systems for this kind of problem. In the case studies, was observed that the implemented tool caused improvements in the analyzed variables: the more standardized distribution of the shipments through the month and the reduction of the cars' average permanence time.

Key-words: Appointment Dock Scheduling, Supply Chain Management, Logistics.

\section{INTRODUÇÃO}

De acordo com Christopher (1997), a logística é o processo de gerenciar estrategicamente a aquisição, movimentação e armazenagem de materiais, peças e produtos acabados (e os fluxos de informações correlatas) através da organização e seus canais de marketing, de modo a poder maximizar as lucratividades presente e futura através do atendimento dos pedidos a baixo custo. Já para Ballou (1993), a logística trata de todas as atividades de movimentação e armazenagem, que facilitam o fluxo de produtos desde o ponto de aquisição de matéria-prima até o ponto de consumo final, assim como dos fluxos de informação que colocam os produtos em movimento, com o propósito de providenciar níveis de serviços adequados aos clientes a um custo razoável.

Pode-se entender, segundo o dicionário da APICS (COX et al., 1995), que Supply Chain ou cadeia de suprimentos é o processo de ligação entre organizações envolvidas no processo de produção de um tipo de bem, do processo da compra inicial de materiais até o último consumidor de um produto final; bem como o conjunto de funções da cadeia de valores responsáveis por produzir e oferecer serviços aos clientes (COX et al., 1995).

Dois conceitos surgiram recentemente no campo da logística, conforme Fleury et al. (2000). O primeiro é o da logística integrada, impulsionada anteriormente na década de 1980 pela revolução da Tecnologia de Informação, dos modelos MRP (Material Requirements Planning) e MRP II (Manufacturing Resource Planning) e do Just in Time (JIT). O segundo é o do Supply Chain Management (SCM), que se apresenta como um conjunto de processos de negócios, como por exemplo, desenvolvimento de novos produtos, que em muito ultrapassa as 
atividades diretamente relacionadas com a logística integrada, apresentando uma abordagem mais ampla, de elevada importância na evolução da logística contemporânea.

Os conceitos atuais de SCM pregam a visão na qual a competição se dá entre cadeias produtivas concorrentes e não mais apenas unidades de negócio concorrentes.

Porter (1992) introduz uma importante mudança de paradigma competitivo, na medida em que considera que a competição no mercado ocorre, de fato, no nível das cadeias produtivas e não apenas no nível das unidades de negócios isoladas. A competição no contexto da SCM, ocorre entre cadeias produtivas, ou seja entre unidade de negócios virtuais, uma combinação entre unidades de negócios de diferentes corporações. Não basta apenas ser eficiente internamente. É preciso que os clientes sejam. É preciso que os fornecedores também sejam. Os fornecedores dos fornecedores também, e assim por diante.

Pires Barros (2002) confirma essa visão ao reconhecer que com as enormes pressões competitivas existentes atualmente, a atividade de gerenciar a cadeia de suprimentos tem tido cada vez mais espaço nas relações de negócios. Propõe ainda, que a competição no mercado ocorre, de fato, no nível das cadeias produtivas e não apenas no das unidades de negócios isoladas.

Segundo Bowersox e Closs (2001), as empresas que obtêm vantagem estratégica baseada em competência logística acabam estabelecendo parâmetros para a concorrência de seu setor.

Como se pode notar, os escopos da logística integrada e do SCM são bastante abrangentes e este trabalho procura explorar aspectos pouco abordados na literatura convencional, a partir das ineficiências no recebimento e expedição de cargas. Essas ineficiências afetam todos os agentes envolvidos nos processos, mas são as transportadoras e operadores logísticos que acabam sentindo os maiores efeitos. Filas e horas de espera ao redor de docas para carregamento e descarregamento têm trazido diversos problemas para a maioria dessas empresas, resultando em um desperdício de ativos e receitas. Como as transportadoras são pagas pelo transporte de mercadorias, isto é, quando seus equipamentos estão rodando e transportando mercadorias, horas paradas e tempos de espera indesejáveis causam um sério impacto para a rentabilidade do negócio. Além disso, há efeitos indiretos, como a insatisfação dos motoristas que acaba gerando uma alta rotatividade dos mesmos (turnover), resultando em prejuízos ainda maiores, uma vez que os custos trabalhistas com desligamentos e contratações, principalmente no Brasil, são bastante elevados.

Filas no carregamento ou recebimento de mercadorias têm uma abrangência muito maior que apenas perda de produtividade para as transportadoras e atrasos nos horários. Afetam, sobretudo, os níveis de estoque ao longo da cadeia de suprimentos, a utilização dos recursos, 
os níveis de capacidade e os custos com a busca de informações. A produtividade perdida resulta em taxas e preços de fretes mais altos para os embarcadores e clientes finais, inseridos nos custos para toda a cadeia de suprimentos.

É nesse cenário que parece fazer sentido um conjunto de medidas para regular o fluxo de veículos por meio do procedimento do agendamento antecipado das docas, baias ou boxes de carregamentos. O presente trabalho procura identificar as práticas tradicionais das empresas frente a essa situação e como algumas empresas têm enfrentado esse desafio.

Para Nemecek (2002), o agendamento antecipado de horários nas docas não deve ser de maneira nenhuma subestimado e entendido apenas como um simples controle e apontamentos de horários. O agendamento com hora marcada, executado de forma acurada e eficiente, pode gerar grandes benefícios para todas as partes envolvidas na cadeia logística, trazendo vantagem competitiva para todos os envolvidos.

\section{MÉTODO}

A presente pesquisa envolve métodos quantitativos, com uso de análises estatísticas, bem como avaliações qualitativas de alguns elementos do estudo.

Neste trabalho, pretende-se responder à seguinte questão de pesquisa: Quais as práticas tradicionais de gestão de docas do carregamento ou recebimento de mercadorias nas empresas e o que as empresas estão fazendo para enfrentar esse desafio?

Para a consecução do presente estudo, utilizou-se dos procedimentos metodológicos de levantamento bibliográfico e estudos de casos em empresas. O trabalho iniciou-se com a apuração de trabalhos e pesquisas anteriores que mostrassem a relevância do problema em questão e o que tem sido feito tradicionalmente pelas empresas para resolvê-lo. Numa segunda etapa, foram investigadas quatro empresas inovadoras que vêem adotando soluções informatizadas para enfrentar esse problema, por meio do método de estudo de caso. A escolha desse método foi feita por ser considerado adequado para uma análise explicativa de problemas reais e contemporâneos (YIN, 2005).

A seleção dessas empresas e do software analisado para a realização do presente artigo, foi feita com base em pesquisas pela Internet de sistemas e empresas que utilizavam tais conceitos. Posteriormente foram realizadas entrevistas abertas e visitas do autor nas empresas selecionadas para levantamento de dados.

Como forma de se verificar as mudanças ocorridas com a implementação do conceito de agendamento suportado por uma ferramenta, elegeu-se dois parâmetros para as análises: 
tempo de permanência dos veículos e distribuição dos carregamentos ao longo do mês. O primeiro se refere ao tempo total que o veículo permanece na empresa, desde sua chegada até saída, incluindo todos os tempos de filas, vistoria, descarga, carregamento, documentação e demais processos de atendimento. A escolha deste parâmetro se justifica pelo reflexo direto nos custos das transportadoras, valores de frete e nível de serviço. O segundo parâmetro diz respeito à concentração dos carregamentos ao longo do mês, de modo que se possa investigar como se comportam as ociosidades e picos dentro do mês. Foi levantada também a distribuição dos carregamentos ao longo do dia, entretanto, devido às dificuldades em se estabelecer comparações por mudanças de horários e freqüentes alterações de turnos, optou-se por analisar apenas a concentração dentro dos dias do mês. Este parâmetro tem impacto direto na eficiência e utilização dos recursos internos. Selecionou-se em cada empresa, o mês de maior movimento, de acordo com a sazonalidade da indústria a qual a empresa está inserida. Os dados foram analisados com o software de análise estatística GraphPad InStat ® v 3.0. O teste aplicado entre os grupos foi a análise de variância (ANOVA) e para análise dos pares dos grupos o teste Tukey-Kramer, ambos utilizando um nível de significância de 5\%. A análise de variância e teste de Tukey-Kramer foram escolhidos para verificar se as diferenças encontradas seriam significantes estatisticamente ou apenas uma variação natural do processo.

Apenas a empresa B autorizou a divulgação completa dos dados sobre tempos de permanência e distribuição dos carregamentos ao longo do mês. Nas demais, as mudanças e benefícios foram relatados pelas pessoas entrevistadas, inclusive no que se refere aos parâmetros analisados, porém o autor não obteve autorização para divulgar.

\section{PROBLEMAS OCULTOS}

Existem diversos problemas com os métodos atuais utilizados para o agendamento de docas e nomeação de horários para transportadoras. A maioria das empresas realiza este procedimento com processos manuais que envolvem mão-de-obra intensiva. Normalmente esses processos fazem uso de papel, telefone, fax e atualmente e-mail. São poucas as empresas que possuem esse procedimento de maneira sistêmica, informatizada e integrada com os sistemas de gestão empresarial, ou os chamados ERPs (Entreprise Resource Planning). O que os principais fornecedores de ERPs do mercado brasileiro, como SAP, Oracle, Microsiga e Datasul oferecem nesse sentido é geralmente superficial, reativo e transacional, ou seja, apenas para registro. Foram encontrados na Internet alguns fornecedores 
estrangeiros com soluções bastante avançadas, tais como DockMaster, SmartDock, OneNetwork, Nistevo, entre outros, mas nenhum deles atua no Brasil.

O que se observa é que os custos de transporte e de logística estão intimamente ligados com esses fatores, principalmente em relação ao frete e mão-de-obra.

Estima-se que no Brasil os gastos com as atividades logísticas correspondam a cerca de $17 \%$ do PIB, com base no fato de que os gastos com transporte correspondem a $10 \%$ do PIB, e que na média o transporte corresponde a $60 \%$ dos custos logísticos. No cenário empresarial, a logística tem importância significativa: os custos logísticos representam cerca de $19 \%$ da receita total, ou seja, mais do que o dobro da margem líquida (8\%). Assim, qualquer redução nos custos logísticos impacta fundamentalmente as margens, ou seja, influenciando diretamente o lucro da organização. (FLEURY et al., 2000 p. $30-31)$.

O trabalho de Nemecek (2002) relata pesquisas realizadas nos Estados Unidos, as quais mostram que a maioria dos embarcadores gasta em média $40 \%$ de seu tempo com nomeações de transportadora, definição e ajustes em horários e respondendo informações por telefone, fax e $e$-mail.

Outro aspecto é que as transportadoras na maioria das vezes são forçadas a se submeter às duras condições impostas pela indústria, grandes atacadistas e distribuidores, como, por exemplo, aguardar com o produto nos caminhões, até o momento mais conveniente. Também há o fato de as nomeações freqüentemente só poderem ser agendadas no horário comercial, pois dependem drasticamente das pessoas envolvidas para estabelecer as regras e condições. Relata-se que $20 \%$ das nomeações e agendamentos têm que ser re-programados, gerando impactos negativos para fornecedores, transportadores e clientes (NEMECEK, 2002).

Os casos mais extremos no Brasil, segundo a visão de fornecedores e transportadores levantada pelo autor, ocorrem com as grandes redes de supermercado, tais como Pão de Açúcar, Wal-Mart e Carrefour, que simplesmente impõem condições de horários que acabam não sendo respeitadas pelas próprias lojas, que acabam utilizando as filas de caminhões como seu estoque de produtos. Assim, como não há comprometimento, nenhumas das partes acaba respeitando e o prejuízo é distribuído por todos na cadeia.

Nemecek (2002) relata que em uma tentativa de reduzir esses prejuízos, uma rede de supermercados nos Estados Unidos, instituiu uma política de cobrar multas para cada agendamento que fosse re-programado mais que duas vezes, seja por atrasos dos fornecedores, transportadores ou de suas próprias lojas. Com isso, chegou a arrecadar entre 
US\$ 7.000 e US\$ 12.000 por mês com as multas aplicadas. Esse exemplo ilustra bem a gravidade desse problema, que por muitas vezes não recebe a devida importância no Brasil.

Problemas com nomeações e agendamento de horários resultam em atrasos e tempos de filas nas docas. Estes atrasos acarretam elevações de custos para embarcadores, transportadoras e clientes. Estudos conduzidos pelo Mercer Management Consulting (2000), nos Estados Unidos, estimam que existe um sobre-preço já absorvido pelo mercado de cerca de $8 \%$ nos valores praticados pelas transportadoras. O fato é que ninguém paga essa conta sozinho. É uma perda para toda a cadeia de suprimentos.

Nemecek (2002) cita a pesquisa “Dry Van Drivers Survey” realizada nos Estados Unidos pela Truckload Carrier Association (TCA), em junho de 1999, a qual mostra que as empresas analisadas perdem cerca de US \$1,6 bilhões ao ano com esperas em torno das docas para entregar ou retirar cargas.

Mesmo dentro da empresa, os efeitos negativos não ficam apenas na expedição ou no recebimento. Segundo relatos nas entrevistas e visitas realizadas durante esta pesquisa, o impacto pode ser sentido principalmente nos níveis de estoque, nos riscos de desabastecimento de uma linha de produção, que pode parar uma fábrica, ou na área comercial, que pode perder vendas, refletindo em última instância no setor financeiro e no fluxo de caixa da empresa. Com o agendamento antecipado, o planejamento e a programação da produção podem ter informações de qual é a ordem exata dos carregamentos e se adequar para produzir o mais próximo possível do momento de retirada, reduzindo assim os níveis de inventário. Por outro lado, sem essa visão, a fábrica pode produzir um lote que já está vendido, mas só será retirado pelo cliente no final da semana, tendo assim um custo desnecessário de manter o estoque. Do mesmo modo, pode acontecer o contrário, ou seja, a transportadora chegar para retirar o produto e este ainda não ter sido produzido, gerando horas paradas.

\section{AGENDAMENTO DE DOCAS: O DESAFIO}

A maioria das empresas no Brasil trabalha sem uma sistemática de agendamento com hora e doca marcadas, de modo que o primeiro a chegar é o primeiro a ser atendido (First InFirst Served). Seria um sistema viável e justo se não houvesse algumas características inerentes ao processo logístico e comercial, principalmente no Brasil, por questões históricas, culturais e fiscais. Na prática, as retiradas e entregas se concentram principalmente no início e final do mês, ocasionando congestionamentos nas docas neste período. Parte desse efeito de 
concentração no final do mês é uma herança do período inflacionário no qual os consumidores necessitavam comprar tudo no início do mês para não perderem o poder de compra. A questão macro-econômica dos altos índices de inflação atualmente não existe mais. Entretanto, esse comportamento enraizou-se na cultura brasileira e se reflete em toda a cadeia produtiva. Outro aspecto que contribui para essa concentração é a política comercial da empresa, que muitas vezes para atingir as metas estabelecidas no mês, incentiva os vendedores a concederem descontos maiores para o atendimento das cotas, causando transtornos para a área de logística e reduzindo a rentabilidade. Além disso, mesmo ao longo do dia, há maior concentração de chegada de veículos pela manhã ou no final da tarde. Assim, seguindo-se a lógica do primeiro a chegar, o primeiro a ser atendido, normalmente acaba ocorrendo um congestionamento nas docas e grandes filas em alguns períodos do dia. Podem ser citados inúmeros outros aspectos encontrados na bibliografia e relatados pelas empresas nos estudos de casos. O fato é que existem fatores que levam à concentração dos carregamentos no final do mês e o objetivo deste artigo é mostrar algumas iniciativas para mudar esse quadro e minimizar seus efeitos. O grande desafio para o sucesso dessa prática é possuir ferramentas que permitam considerar essas diversas restrições, conciliando os interesses dos embarcadores, transportadores e clientes, de maneira ágil e confiável.

A logística ainda é um dos grandes gargalos na cadeia de suprimentos. Ineficiências dos agentes envolvidos, recursos mal dimensionados e mal distribuídos são alguns dos pontos mais vulneráveis de toda a cadeia. Além de obter excelência interna, indústria, atacado, distribuidores, operadores logísticos e transportadores precisam trabalhar em sintonia. Atrasos causados por fatores climáticos, congestionamentos e falhas mecânicas podem acontecer e é nesse ponto que surge a necessidade de um sistema informatizado, de preferência via Web, que esteja acessível a qualquer lugar e a qualquer hora.

\section{DESCRICÃO DOS CASOS}

Os estudos de casos das empresas descritos a seguir ilustram o gerenciamento e controle das operações de carga e descarga a partir do agendamento antecipado de docas com hora marcada, bem como a implantação de procedimentos e práticas para sua viabilização, suportado por uma mesma ferramenta informatizada. Foram encontradas outras empresas que trabalham com os mesmos conceitos, entretanto, a maioria delas não utilizava um software específico para isto, fazendo seus controles por processos manuais, planilhas ou por meio de desenvolvimento interno. A empresa que desenvolveu o software está situada no interior do 
estado de São Paulo, em Ribeirão Preto e chama-se Logística e Processos Ltda. Três das empresas usuárias do sistema pesquisadas estão localizadas na região de Ribeirão Preto, em um raio de 150 km e duas estão situadas na região da Grande São Paulo.

O nome comercial do software é MONILOC ${ }^{\circledR}$ e, segundo Lotufo (2003), é uma solução inovadora que otimiza variáveis pouco exploradas na gestão tradicional de logística e transportes, tais como o agendamento de docas e seu monitoramento, balanceamento do fluxo dos veículos e a minimização dos chamados "tempos mortos" (esperas, filas, carga e descarga). Lotufo (2003) explica que o MONILOC ${ }^{\circledR}$ otimiza o uso da estrutura interna com o agendamento antecipado das viagens, permitindo todo o controle de entradas e saídas de cargas, podendo ser parametrizado para diversos tipos de carregamento, tipos de veículos, produtos e embalagens. Permite ainda reduzir a ociosidade das docas de carga/descarga e adequá-las para picos de utilização, através de um algoritmo de seqüenciamento e programação das grades de horários. Ele também descreve uma série de características técnicas da ferramenta, que além das funcionalidades operacionais, também possui consultas, relatórios e gráficos para análise das operações.

Segue abaixo a relação das empresas selecionadas para esse estudo de caso que utilizam o sistema:

- Empresa A: Empresa nacional do setor de alimentos e bebidas, líder de mercado, com faturamento anual superior a 200 milhões de reais.

- Empresa B: Empresa nacional do setor de alimentos e bebidas, fabricante de marca multinacional líder de mercado, com faturamento anual superior a 400 milhões de reais.

- Empresa C: Empresa nacional do setor de papel e celulose, atuando na produção de papéis para higiene e limpeza, com faturamento anual superior a 200 milhões de reais.

- Empresa D: Empresa multinacional de origem alemã líder no setor automotivo, com faturamento no Brasil superior a 1 bilhão de reais.

A empresa A, utiliza o agendamento de docas para a expedição de seus produtos a partir de duas unidades industriais e cinco Centros de Distribuição (CDs). De acordo com Walb (2003), cerca de $80 \%$ dos produtos vendidos pela empresa A são retirados pelo próprio cliente, fato que ocasionava imensas filas de caminhões e esperas no carregamento, além da concentração de vendas no final do mês. A primeira conseqüência desse acesso desorganizado era o congestionamento do carregamento. Walb (2003) cita ainda que outra conseqüência era o fato de a área industrial não conseguir controlar com precisão o retorno dos vasilhames retornáveis. Assim, a empresa A, precisava de uma ferramenta para auxiliá-la a programar de 
maneira mais eficiente seus recursos de expedição, a fim de atender a chegada aleatória de veículos para retirar cargas. Hoje, com o sistema, Walb (2003) relata que a empresa consegue saber com antecedência, além dos itens comprados e embalagens que serão retornadas, qual veículo será usado, se a operação será paletizada ou manual e quando ocorrerá. O sistema prevê o agendamento a partir do pedido do cliente. Por meio de uma central de atendimento, os clientes ligam para agendar o horário a partir de uma série de restrições, tais como, data desejada, tipo de carga, tipo de veículo a ser enviado, entre outras. Em seguida, o operador então visualiza no sistema quais são as docas disponíveis para aquele tipo de operação e qual a sua disponibilidade de horário, podendo deixar que o sistema sugira a melhor doca e horário, ou então escolha dentre as possíveis alternativas. O horário é comunicado ao cliente e à transportadora que deve chegar na empresa com a antecedência pré-estabelecida para efetuar o check in e não comprometer o horário agendado. A partir daí, entra em ação o módulo de monitoramento que acompanha todo o processo, comparando os horários previstos e realizados de cada fase, permitindo apontar não-conformidades e efetuar re-programações. O volume de carregamentos é da ordem de 1.900 veículos por mês. Com a implantação do sistema, Walb (2003) cita que a empresa conseguiu um aumento de $30 \%$ na capacidade de expedição, com a mesma estrutura, e os veículos permanecem $25 \%$ menos tempo na empresa. Outros ganhos também podem ser citados, como maior giro do estoque e maior visibilidade dos gargalos. Para Campos (2004), com o agendamento das retiradas de mercadorias, a empresa A presta um serviço diferenciado aos clientes distribuidores e aumenta a fidelização. "O que faz a diferença aqui é o tratamento. Aqui é 24 horas, o estacionamento é seguro e seu eu carrego com hora marcada posso até fazer mais viagens", relata um motorista no trabalho de Campos (2004).

A empresa B, também do setor de alimentos e bebidas, utiliza o sistema para programar e acompanhar os carregamentos das vendas para outras fábricas do grupo a partir de uma planta industrial. Foi observado nas visitas e entrevistas que o sistema contempla a previsão de venda colaborativa, a colocação do pedido, seu agendamento por meio de central de atendimento e acompanhamento de cada etapa. A partir do planejamento da capacidade de docas e expedição, para cada tipo de veículo, tipo de operação (manual ou paletizada) ou tipos de produtos e horários, o sistema disponibiliza e monta as grades de horários, de modo a otimizar sua utilização, evitando ociosidade ou sobrecarga. O processo todo é semelhante à empresa A, com o diferencial de que os clientes e transportadoras podem monitorar pela Internet em tempo real a situação dos carregamentos e obter informações sobre o desempenho 
da operação, de acordo com os perfis dos usuários. Além disso, o sistema está integrado com o WMS (Warehouse Management System) da empresa, para checar no momento do agendamento se há produto disponível em estoque para aquele carregamento. $\mathrm{O}$ número médio de agendamentos é de 300 veículos por mês.

Como resultados, em dois anos de operação, a empresa conseguiu uma melhor distribuição dos carregamentos ao longo do mês, como se pode observar no gráfico 1, na comparação dos períodos de dezembro 2000/2001 (sem agendamento) com dezembro 2002/2003 (com o sistema já implantado). Pode-se notar que houve um aumento do número de carregamentos e, ao mesmo tempo, regularizou-se a distribuição dos carregamentos ao longo do mês, antes concentrado entre os dias 10 e 20 do mês. O gráfico 1 mostra esse comportamento para o mês de dezembro, mês de pico nas vendas, embora comportamento semelhante foi encontrado analisando-se outros meses.

Gráfico 1: Quantidade de carregamentos no mês na empresa B, com e sem agendamento

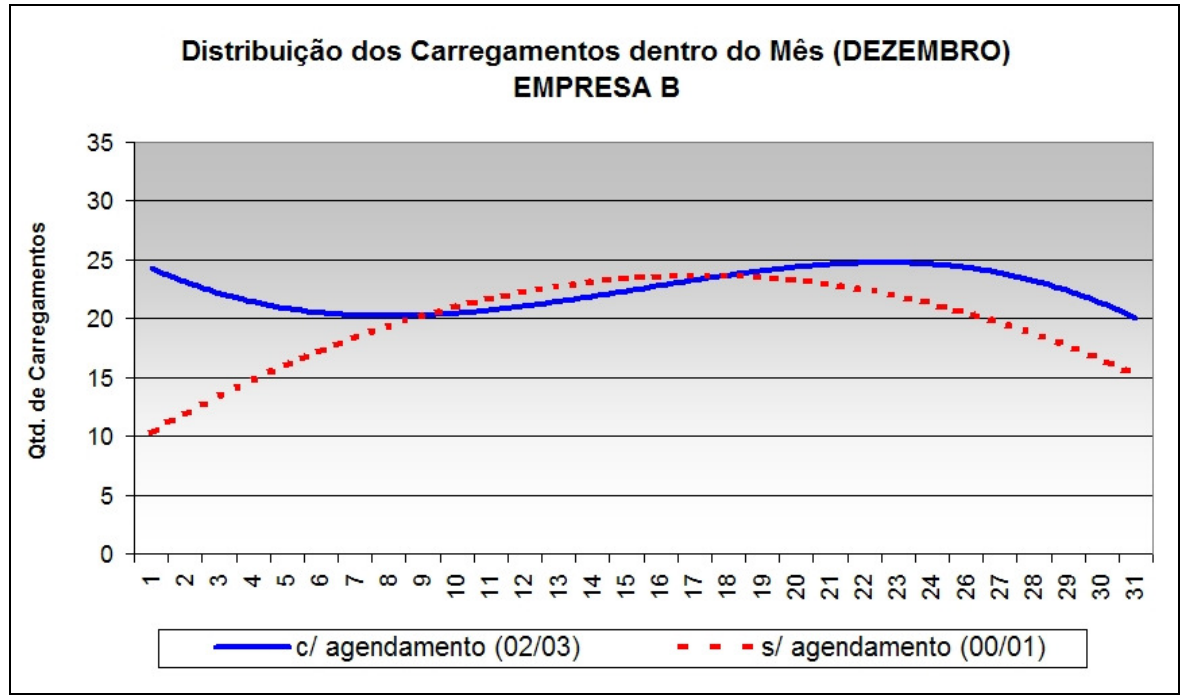

Fonte: do autor

$\mathrm{Na}$ análise do tempo que os veículos permanecem na empresa para efetuar os carregamentos, desde a chegada na portaria até a saída com a carga, com dados de maio de 2002, 2003 e 2004, observa-se uma redução de aproximadamente 26\% no tempo de maio/04 em relação à maio/02, conforme ilustra o gráfico 2 (redução de 6,266 horas para 4,602 horas). Essa redução foi estatisticamente significante, de acordo com os testes realizados e relatados a seguir. Foi escolhido o mês de maio pelo fato da empresa B ter começado a registrar esses tempos apenas a partir de maio de 2002. Vale destacar que esses dados referem-se aos tempos 
já com o sistema em operação. Segundo depoimentos coletados, antes da implantação do sistema, os tempos médios de permanência eram cerca de uma a duas horas superiores ao início da implantação, mas a empresa $\mathrm{B}$ não possuía registro desses tempos para comprovação.

Gráfico 2: Evolução do tempo total de permanência dos veículos na empresa B

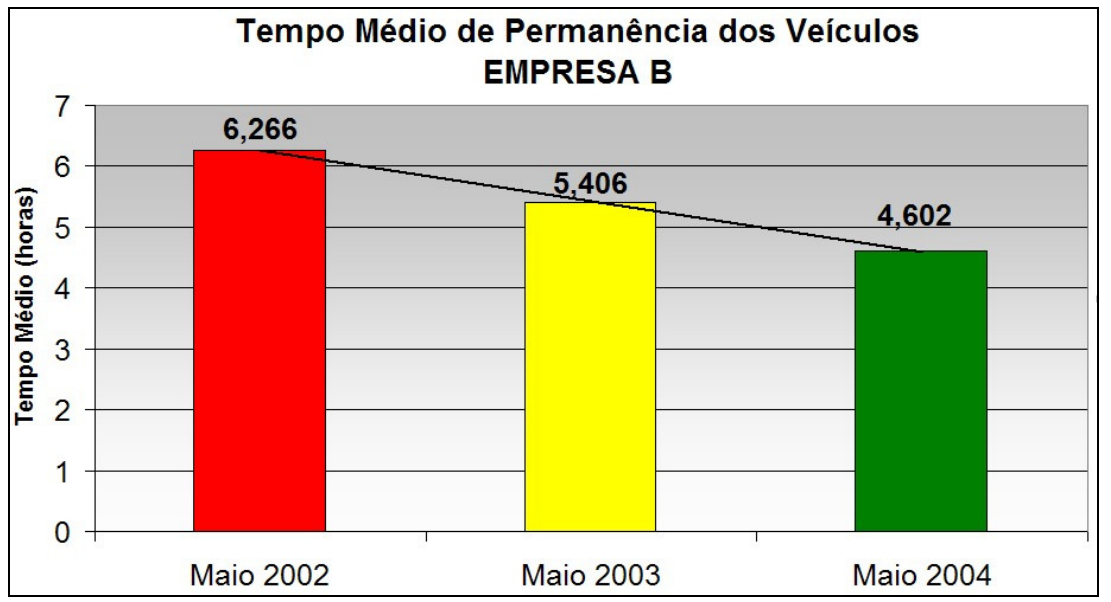

Fonte: do autor

A tabela 1 apresenta o número da amostra, o tempo médio, desvio padrão, erro padrão da média e o valor da mediana, para cada grupo. Já na tabela 2 têm-se os valores mínimo, máximo e o intervalo de confiança para $95 \%$ dos dados.

Tabela 1: Comparação dos tempos de permanência entre os grupos analisados

\begin{tabular}{cccccc}
\hline Group & $\begin{array}{c}\text { Number of } \\
\text { Points }\end{array}$ & Mean & $\begin{array}{c}\text { Standard } \\
\text { Deviation }\end{array}$ & $\begin{array}{c}\text { Standard Error } \\
\text { of Mean }\end{array}$ & Median \\
\hline Maio 2002 & 266 & 6.266 & 4.832 & 0.2963 & 5.030 \\
Maio 2003 & 352 & 5.406 & 2.596 & 0.1384 & 4.967 \\
Maio 2004 & 322 & 4.602 & 2.506 & 0.1397 & 3.905 \\
\hline
\end{tabular}

Fonte: do autor, com auxílio do software GraphPad InStat ${ }^{\circledR}$

Tabela 2: Outras comparações dos tempos de permanência entre os grupos analisados

\begin{tabular}{ccccc}
\hline \multirow{2}{*}{ Group } & \multirow{2}{*}{ Minimum } & \multirow{2}{*}{ Maximum } & $\begin{array}{c}\text { 95\% Confidence } \\
\text { From }\end{array}$ & $\begin{array}{c}\text { Interval } \\
\text { To }\end{array}$ \\
\hline Maio 2002 & 1.3550 & 36.399 & 5.685 & 6.846 \\
Maio 2003 & 0.2286 & 18.868 & 5.134 & 5.677 \\
Maio 2004 & 1.4620 & 21.446 & 4.328 & 4.876 \\
\hline
\end{tabular}

Fonte: do autor, com auxílio do software GraphPad InStat 
$\mathrm{Na}$ análise, por meio do teste de comparação múltipla de Tukey-Kramer, observou-se que existe diferença significativa entre os grupos de maio/02 e maio/03 ( $\mathrm{p}<0,01)$, assim como os grupos maio/03 e maio/04 ( $\mathrm{p}<$ 0,001). Entre os grupos maio/02 e maio/04 foi comprovado que existe diferença muito significativa $(\mathrm{p}<0,001)$. Essas informações encontram-se explicitadas na tabela 3 .

Tabela 3: Teste de Comparação Múltipla Tukey-Kramer

\begin{tabular}{cccc}
\hline Comparison & Mean Difference & $q$ & $P$ value \\
\hline Maio 2002 vs Maio 2003 & 0.8602 & 4.458 & $* * \mathrm{P}<0.01$ \\
Maio 2002 vs Maio 2004 & 1.6640 & 8.454 & $* * * \mathrm{P}<0.001$ \\
\hline Maio 2003 vs Maio 2004 & 0.8033 & 4.368 & $* * \mathrm{P}<0.01$ \\
\hline
\end{tabular}

Fonte: do autor, com auxílio do software GraphPad InStat

Dessa forma, pode-se concluir que o sistema de agendamento influenciou na redução significativa do tempo de permanência dos veículos na empresa, durante os três anos de operação. Além disso, segundo informações coletadas, houve a redução de um turno de carregamento, re-alocando o pessoal para outras atividades.

Outros benefícios também podem ser citados, como a redução de horas extras com os funcionários da expedição, redução de filas para as transportadoras, melhor uso de seus ativos e o melhor planejamento para a área comercial e produção, a partir do conhecimento antecipado das previsões e dos carregamentos agendados previamente.

A empresa $\mathrm{C}$, do setor de papel e celulose, também utiliza o sistema para expedir seus produtos para grandes clientes, distribuidores e clientes preferenciais, a partir de duas plantas industriais. O processo também é semelhante aos casos anteriores e a integração acontece com o ERP corporativo da empresa para dados dos pedidos e lotes que devem ser agendados.

A versão do sistema que está implantado nessa empresa apresenta uma evolução em relação às anteriores no que diz respeito ao algoritmo para a montagem da grade e dos agendamentos, pois considera horários dinâmicos, de acordo com o tipo de veículo, tipo de operação e tipos de produtos, ou uma combinação desses fatores. Por exemplo, se o agendamento é para um veículo tipo carreta e a operação é manual, o sistema reserva 60 minutos na grade de horários. Para uma carga com um veículo tipo truck e operação paletizada (embalagens de madeira que facilitam a movimentação), o sistema reserva 30 minutos. Assim é possível combinar as variáveis do agendamento para se chegar ao tempo padrão a ser reservado no sistema. Como resultados, observou-se o melhor aproveitamento 
dos recursos físicos e humanos, a fidelização dos clientes pelo maior nível de serviço prestado, a maior produtividade das transportadoras e a redução das filas de veículos que ficavam na área externa da empresa atrapalhando o trânsito e aumentando o risco de acidentes na rodovia.

Já a empresa D utiliza o sistema de agendamentos para gerenciar todo o Inbound das suas quatro plantas industriais, ou seja, programar todo o recebimento de peças e componentes de seus fornecedores. Segundo Malinverni (2003), a maioria dos transportes é a própria empresa D que tem a responsabilidade de coletar diretamente nos seus fornecedores. Há uma grande variedade de modalidades de transporte para essas operações, como, por exemplo, coletas Milk Run ${ }^{1}$, coletas preliminares ${ }^{2}$, coletas Kanban $^{3}$, cargas consolidadas ${ }^{4}$, entregas $\mathrm{CIF}^{5}$ dos próprios fornecedores, viagens emergenciais ${ }^{6}$, transferência interplantas ${ }^{7}$, entre outras, todas contempladas no sistema, com implicações e ações diferentes, mas todas com agendamentos de docas e monitoramento.

O fluxo básico do processo descrito por Malinverni (2003) é o seguinte: a empresa D envia aos fornecedores e aos operadores logísticos o Release das peças ou "chamada de peças", isto é, a programação do que deve ser coletado na semana. Os fornecedores confirmam a coleta até às $18 \mathrm{~h} 00$ do dia anterior à coleta e repassam às transportadoras contratadas via sistema, que está em plataforma Internet, ágil e barata. De posse das rotas e peças a serem coletadas, as transportadoras fazem a programação das viagens no sistema e programam os agendamentos de coleta no fornecedor e de entrega na fábrica, de acordo com as restrições estabelecidas pela empresa D.

O próprio sistema já identifica qual a doca mais adequada para cada operação e monta a grade de horários, de acordo com Maliverni (2003), pois no sistema de agendamento de docas está parametrizada toda a estrutura logística da empresa, com informações sobre as mais de 100 docas e sua distribuição pelas fábricas, a capacidade de cada uma delas, os turnos de trabalho e horários em que não devem operar, como parada de almoço e troca de turno, por exemplo. Também são identificados os tipos de caminhões que recebem e de equipamentos da operação (empilhadeiras, ponte rolante ou manual), bem como todas as restrições da estrutura de logística. Malinverni (2003) relata ainda que entre essas docas, será escolhida a que apresentar o melhor desempenho para a operação.

Uma vez agendada a doca, a grade de recebimento da carga é montada e repassada ao transportador e ao fornecedor, para conhecimento dos horários em que as peças deverão ser coletadas. Os fornecedores, por sua vez, enviam o arquivo ASN Anfavea 04, ou seja, o Aviso 
Antecipado de Embarque, uma transação eletrônica de comunicação da nota fiscal para confirmar o processo.

Graças ao agendamento, a empresa D sabe, exatamente, o volume que será coletado, quantos veículos chegarão à fábrica no dia seguinte, horários das janelas e ocupação das docas. A partir daí ocorre a fase de monitoramento, isto é acompanhar se as operações estão saindo como o planejado e corrigir possíveis desvios. Esse apontamento é feito por cartões magnéticos que os motoristas recebem na entrada da fábrica e devem passar em cada leitor localizado nas docas e pontos de descargas para controle dos tempos. O volume das operações é de 600 agendamentos por dia, com potencial para chegar em até 1.500 veículos por dia, nas quatro fábricas. O sistema está integrado com outros sistemas, como por exemplo, o WMS $\left(\right.$ Pluma ${ }^{\circledR}$ ), sistema de coletores de cartão magnético, sistema de pagamento e auditoria de fretes $\left(\mathrm{GKO}\right.$ Fretes ${ }^{\circledR}$ ), sistema de embalagens (LISON ${ }^{\circledR}$ ), diversos sistemas das transportaras e servidores de $e$-mail.

Malinverni (2003) cita como benefícios, a redução dos "tempos mortos", redução de custos logísticos, automação de procedimentos manuais, melhoria no controle de fluxo de informações e maior transparência do processo. Completa ainda que devido a esses agendamentos, a empresa sabe, exatamente, o volume que será coletado, quantos caminhões chegarão às fábricas no dia seguinte, horários e janelas de ocupação das docas, reduzindo assim o risco de parada de uma linha de montagem por falta de material.

O segundo revisor pede que seja explicado melhor o método estatístico usado nos casos.

\section{DISCUSSÃO}

A definição de SCM é uma evolução natural do conceito de logística integrada. Enquanto a logística integrada representa uma coerência interna de atividades, o SCM representa suas conexões externas com outras empresas. Isso também nos remete à evolução do pensamento logístico. A cada momento, a prática da logística reflete e ao mesmo tempo alimenta o pensamento logístico, em uma criativa interação entre o meio acadêmico e o meio empresarial. No entanto, o pensamento logístico é composto por conceitos e teorias que orientam o estudo e a pesquisa nessa área, influenciando o que se considera relevante e justificando as soluções propostas para os problemas logísticos. Em linhas gerais, o campo da logística evoluiu de um tratamento mais restrito, voltado para a distribuição física de materiais e bens, para um escopo mais abrangente, em que se considera a cadeia de suprimentos como um todo e as atividades de compras, administração de materiais e distribuição. Atualmente, as 
empresas de classe mundial vêm sofrendo um achatamento em suas margens de lucros, devido à intensa competição e ao interesse do consumidor por preços mais baixos. Tal situação vem pressionando as organizações a intensificar o controle de custos internos e a melhorar o serviço ao cliente (BERMAN, 1998; ELLRAM et al., 1999). De acordo com Lambert, Stock e Vantine (1998), uma empresa típica costuma ser o terceiro custo operacional em valor e é a área mais promissora para se obter economia significativa de custos, especialmente no Brasil. É nesse cenário que o agendamento de docas, aliado à otimização dos recursos internos, ao planejamento antecipado e ao melhor nível de serviço oferecido aos parceiros de negócio, se enquadra como uma ferramenta para viabilizar a filosofia do SCM e reduzir custos.

Para Arnold e Chapman (1999) dentro da cadeia de suprimentos ou SCM, existem três fases no fluxo de materiais. Matérias-primas e insumos fluem para uma empresa fabricante com base em um sistema de suprimento físico ou recebimento, são processados pela produção e, finalmente, produtos acabados são expedidos para os clientes finais por meio de um sistema de distribuição física. Foi constatado que o agendamento de docas pode ser útil na coordenação tanto das entradas (inbound), como saídas (outbound), integrado aos outros processos, de acordo com a figura 1.

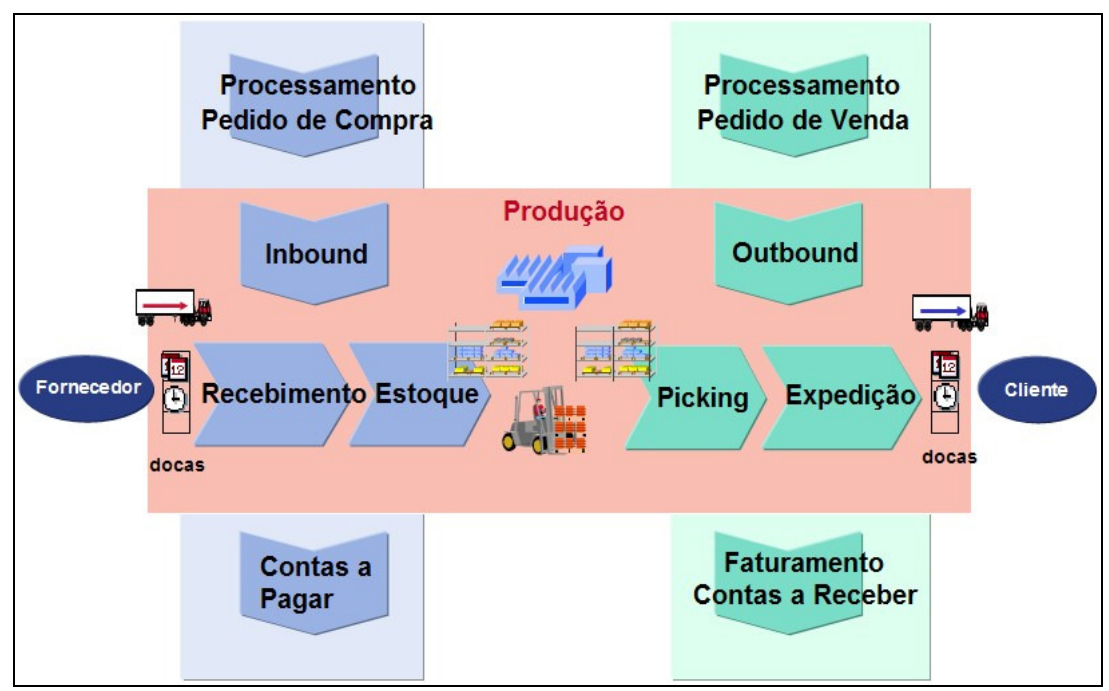

Figura 1: Processos do SCM envolvidos no agendamento de docas

Fonte: do autor

Neste trabalho, identificam-se alguns prejuízos que a falta de uma melhor organização do recebimento e da expedição pode causar à cadeia de suprimentos. Uma das soluções 
encontradas para melhor planejar, organizar e monitorar esses processos é a execução do agendamento antecipado de docas. Tal procedimento já está consolidado nos Estados Unidos, mas encontra-se ainda incipiente no Brasil. Verificaram-se nos estudos de casos algumas empresas que já vêm implantando essa sistemática por intermédio de ferramentas informatizadas e tecnologias avançadas com bastante sucesso.

Segundo Bowersox e Closs (2001), a idéia básica de competitividade na cadeia de suprimentos tem dois princípios: a convicção fundamental de que o comportamento cooperativo irá reduzir o risco aprimorando a eficiência de todo o processo logístico e a eliminação do trabalho duplicado e inútil.

Ballou (1993) afirma que comunicações lentas e imprecisas podem custar muito caro para as organizações, pois se transformam em vendas perdidas; os estoques tornam-se excessivos, o transporte fica imprevisível e a programação da produção pode gerar preparações desnecessárias e custosas.

\section{CONCLUSÕES}

Nos estudos de casos, observou-se como comprovado pelas análises estatísticas de variância (ANOVA), através do teste de Tukey-Kramer, que a ferramenta implementada trouxe melhorias significativas nas variáveis analisadas, ou seja, na distribuição mais uniforme dos carregamentos ao longo do mês e na redução do tempo médio de permanência dos veículos. Outros benefícios indiretos foram observados, de modo que a prática do agendamento parece ser um fator regulador de todo o processo logístico.

De um modo geral, o agendamento por si só já é um fator de vantagem competitiva, mas é apenas a ponta do iceberg que atua como uma espécie de regulador dos fluxos de entrada e saída de materiais. O processo de agendamento bem feito implica que os processos anteriores estejam bem sincronizados e os processos subseqüentes tendem a serem mais previsíveis.

Além disso, um sistema de agendamento pode colaborar na identificação e minimização de gargalos, que irá ter impacto em toda a cadeia de distribuição. Pode-se dizer que o software de agendamento antecipado de docas analisado atua segundo a Teoria das Restrições (Theory of Constraints-TOC) de Goldratt (1997), a qual diz que se deve balancear o fluxo e não os recursos. Assim, as restrições do processo ficam visíveis e podem ser atacadas, até que surjam novas restrições. Esses conceitos foram identificados nas empresas que implementaram o sistema, uma vez que os carregamentos estão sujeitos à disponibilidade de docas e horários parametrizados para cada período e não o contrário. Uma regra clara que foi encontrada em 
todos os casos estudados é que somente os veículos com horário agendado, são liberados para carregar ou descarregar, não permitindo carregar mais do que a capacidade instalada.

Nesse sentido, são identificadas semelhanças com a filosofia TOC, a qual sugere a ênfase no fluxo de materiais e não na capacidade dos recursos. Com o sistema, procura-se programar o fluxo de veículos de acordo com a disponibilidade de recursos. Tradicionalmente, o que as empresas têm feito é exatamente o contrário, ou seja, adaptar os recursos ao fluxo de veículos. É uma mudança de cultura e de paradigma.

Portanto, conclui-se que o agendamento de docas é uma ferramenta bastante poderosa, atuando na comunicação, no planejamento colaborativo, na otimização de recursos, na melhor previsibilidade e na automação de tarefas repetitivas. Cabe salientar, que esta técnica pode viabilizar e complementar outras iniciativas, tais como o CPFR (Collaborative Planning Forecast and Replishment), ECR (Efficient Customer Response) e VMI (Vendor Management Inventory) além do próprio conceito do Supply Chain Management.

\section{CONTRIBUIÇÕES FUTURAS}

É importante destacar que os casos das empresas aqui apresentados, são uma pequena amostra da aplicação e benefícios do agendamento de docas. Fica evidente que é necessário se analisar outros aspectos e impactos relacionados com a prática do agendamento antecipado, seja nas empresas analisadas ou em outras.

Para trabalhos futuros, sugere-se a investigação de outras variáveis que comprovem os benefícios com a utilização desse tipo de solução, incluindo principalmente a perspectiva financeira.

Além disso, seria de grande valor pesquisar iniciativas em outros países com resultados e potenciais de ganhos, bem como levantamento mais detalhado e a análise comparativa dos softwares de agendamento de docas existentes no mercado brasileiro e internacional. 


\section{REFERÊNCIAS BIBLIOGRÁFICAS}

ARNOLD, J.R.; CHAPMAN, S.N. Introduction to Materials Management. Colombus: Prentice Hall, 2001.

BALLOU, Ronald H. Logística Empresarial. São Paulo: Atlas, 1993.

BERMAN, B. Retail management: a Strategic Approach. 7. ed. Englewood Cliffs: Prentice Hall, 1998.

BOWERSOX, Donald J.; CLOSS, David J. Logística Empresarial: o processo de integração da cadeia de suprimento. São Paulo: Atlas, 2001.

CAMPOS, V. Mais uma Boa Idéia. Revista Distribuição, São Paulo, ano XI, n. 133, p. 3537, fev. 2004.

CHRISTOPHER, M. Logística e Gerenciamento de Cadeia de Suprimentos. São Paulo: Pioneira, 1997.

COX, J.F.; BLACKSTONE, J.H.; SPENCER, M.S. APICS Dictionary. 8. ed. Falls Church: American Production and Inventory Control Society, 1995.

ELLRAM, L. M.; LA LONDE, B.; WEBER, M. M. Retail Logistics. International Journal of Phisical Distribuction and Logistics Management, v.29, n. 7/8, 1999.

FLEURY, Paulo F. et al. Logística Empresarial: a perspectiva brasileira. Organização: Paulo F. Fleury, Peter Wanke, Kleber F. Figueiredo. Coleção COPPEAD de Administração. São Paulo: Atlas, 2000.

GOLDRATT, Eliyahu M.; COX, Jeff. A meta: um processo de aprimoramento contínuo. São Paulo: Editora Educator, 1997.

LAMBERT, Douglas M.; STOCK, James R.; VANTINE, José Geraldo. Administração Estratégica da Logística. São Paulo: Vantine Consultoria, 1998.

LOTUFO, Fabio R. Agendamento de Horários em Indústria de Bebidas. 2003. Trabalho de Conclusão de Curso (Especialização em Administração) - FUNDACE, Ribeirão Preto, 2003.

MALINVERNI, Cláudia. Volkswagen Implanta Sistema de Transporte Inteligente. Revista Tecnologística, São Paulo, ano IX, n. 94, p. 28-36, set. 2003.

MERCER MANAGEMENT CONSULTING. Just in Time to Wait: An Examination of Best Practices for Streamlining Loading/Unloading Functions. EUA: jul. 2000. 
NEMECEK, Rachel. Appointment Scheduling: Achieving the Positive Ripple Effect. New York : Elogex, Feb. 2002.

PIRES BARROS, F.E. Gerenciamento da Cadeia de Suprimentos: Tendências da Indústria Automobilística Brasileira. Centro de estudos em logística. Disponível em: <www.cel.coppead.ufrj.br/fs-public.htm>. Acesso em: 10 set. 2002.

PORTER, M. E.. Vantagem Competitiva: criando e sustentando um desempenho superior. Rio de Janeiro: Campus, 1992.

WALB, Lílian. Uma Boa Idéia de Logística. Revista Alimentos e Bebidas, São Paulo, p. 5657, jan./fev. 2003.

YIN, Robert. Estudo de Caso: Planejamento e Métodos. Porto Alegre: Bookman, 2005.

\footnotetext{
${ }^{1}$ Coleta Milk Run é uma denominação de viagens muito comuns na indústria automobilística na qual o transportador programa rotas de coleta em vários fornecedores próximos a fim de otimizar o percurso e a utilização de capacidade do veículo, baseado no conceito americano de entrega de leite e coleta de garrafas vazias no passado.

${ }^{2}$ Coletas preliminares são viagens nas quais o transportador coleta pequenos volumes em diversos fornecedores com veículo pequenos e os consolida em um depósito intermediário até completar uma carga em um veículo maior e mais econômico.

${ }^{3}$ Coletas Kanban são transportes originados por meio de solicitações Kanban (cartão, em japonês) da linha de montagem, originados do Sistema Toyota de Produção através de cartões, baseado na necessidade.

${ }^{4}$ Cargas consolidadas são as viagens de um depósito intermediário para a montadora em veículos maiores e mais econômicos consolidando várias mercadorias.

${ }^{5}$ CIF é uma expressão do transporte internacional (INCOTERM) utilizada amplamente no Brasil também para transportes internos que significa Custo, Seguro e Frete (Cost, Insurance and Freigth) para indicar que a mercadoria cotada já está com tudo embutido no seu preço final e o fornecedor é responsável pelo transporte.

${ }^{6}$ Viagens emergenciais são transportes não programados e urgentes para evitar falta de estoque devido a erros de programação. Geralmente são mais caras e devem ser evitados.

${ }^{7}$ Transferência interplantas são viagens para transportar mercadorias entre unidades da mesma empresa.
} 